\section{Does infrared or ultraviolet light damage the lens?}

PG Söderberg, N Talebizadeh, Z Yu and

K Galichanin

\begin{abstract}
In daylight, the human eye is exposed to long wavelength ultraviolet radiation (UVR), visible radiation and short wavelength infrared radiation (IRR). Almost all the UVR and a fraction of the IRR waveband, respectively, left over after attenuation in the cornea, is absorbed in the lens. The time delay between exposure and onset of biological response in the lens varies from immediate-to-short-to-late. After exposure to sunlight or artificial sources, generating irradiances of the same order of magnitude or slightly higher, biological damage may occur photochemically or thermally.

Epidemiological studies suggest a dosedependent association between short wavelength UVR and cortical cataract. Experimental data infer that repeated daily in vivo exposures to short wavelength UVR generate photochemically induced damage in the lens, and that short delay onset cataract after UVR exposure is photochemically induced. Epidemiology suggests that daily high-intensity short wavelength IRR exposure of workers, is associated with a higher prevalence of age-related cataract. It cannot be excluded that this effect is owing to a thermally induced higher denaturation rate. Recent experimental data rule out a photochemical effect of $1090 \mathrm{~nm}$ in the lens but other wavelengths in the near IRR should be investigated.
\end{abstract}

Eye (2016) 30, 241-246; doi:10.1038/eye.2015.266; published online 15 January 2016

\section{Introduction}

The present review covers effects of moderate intensities of ultraviolet and infrared radiation in the crystalline lens that may occur after exposures to the sun or artificial sources causing a comparable irradiance on the eye. If the lens is exposed to high-intensity sources, additional action mechanisms not covered here have to be considered.

Spectral radiation from the sun on the earth Because of the high temperature of the sun, electromagnetic radiation within a broad waveband is emitted. At the sun temperature, there is a peak emission of visible radiation (VIR) that tapers off towards shorter than visible UVR wavelengths, and towards longer than visible infrared wavelengths as described by Planck's radiation. The radiation emitted from the sun is spectrally attenuated in the atmosphere before reaching the surface of the earth, so that wavelengths below $290 \mathrm{~nm}$ and above $2500 \mathrm{~nm}$ are essentially blocked out (Figure 1). The ocular spectral exposure additionally depends on solar elevation and background reflection ${ }^{1}$ and the exposure geometry of the eye. ${ }^{2}$

The spectral sensitivity of the visual system depends on the irradiance on the retina but typically VIR is defined as wavelengths between 400-760 nm. Electromagnetic radiation with wavelengths shorter than VIR but longer than $\mathrm{X}$-rays is referred to as ultraviolet radiation (UVR), and the waveband with wavelengths longer than VIR but shorter than microwaves is denoted as infrared radiation (IRR). UVR from the sun reaching the surface of the earth is commonly split into a spectral band with short wavelengths, UVR-B, or intermediate UVR, and a spectral band with long wavelengths, UVR-A, or near UVR.

Attenuation of solar radiation in the anterior part of the eye

The human cornea blocks solar radiation with wavelengths shorter than $290 \mathrm{~nm}$ (Figure 2). ${ }^{3}$ The lens absorbs essentially all the UVR and, age dependently, shorter VIR wavelengths that are

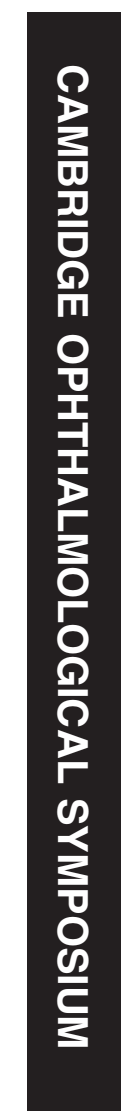

Department of Neuroscience, Ophthalmology, Gullstrand laboratory, Uppsala University Hospital, Uppsala, Sweden

Correspondence: PG Söderberg, Department of Neuroscience, Ophthalmology, Gullstrand laboratory, Uppsala University Hospital, SE-751 85 Uppsala, Sweden Tel: +46186119990 or +46708 4184 47; E-mail: per.soderberg@ ophthalmology.neuro.uu.se

Received: 8 September 2015 Accepted in revised form: 18 November 2015 Published online: 15 January 2016

This work was presented at the Cambridge Ophthalmological Symposium 2-5 September 2015. 


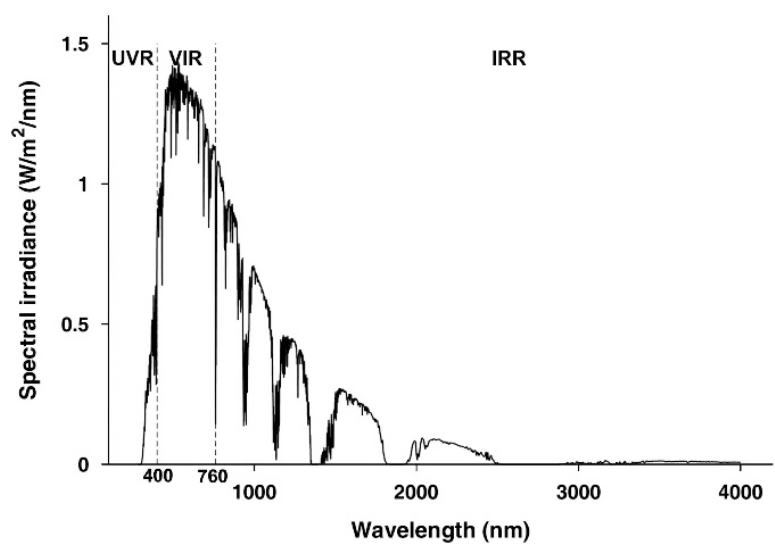

Figure 1 Direct spectral irradiance on the surface of the earth (ASTM G173-03) in the ultraviolet radiation (UVR) waveband, the visible radiation (VIR) waveband and the infrared radiation (IRR) waveband.

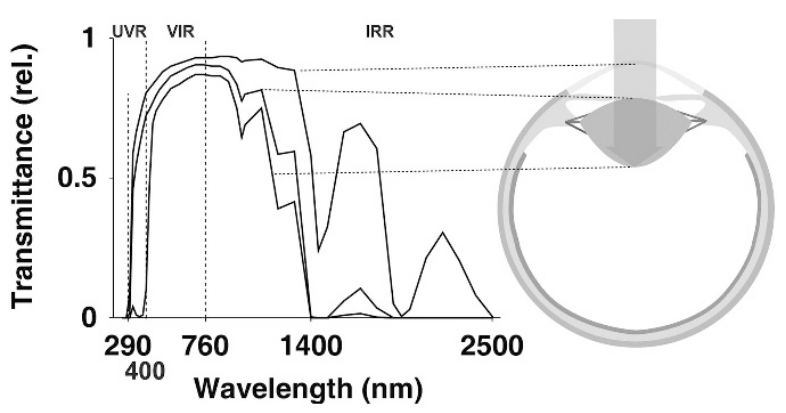

Figure 2 Transmittance of the anterior segment of the eye. ${ }^{3}$ The upper, middle and lower curve, respectively, is transmittance to the posterior surface of the cornea, to the anterior surface of the lens and to the posterior surface of the lens.

transmitted by the cornea, and then absorbs with a characteristic spectrum in the near IRR. It has been demonstrated with in vivo measurements using intrinsic lactate dehydrogenase as a sensor that UVR in the $300 \mathrm{~nm}$ wavelength region has a penetration depth of around $0.5 \mathrm{~mm} .^{4}$

Time delay between exposure to electromagnetic radiation and response in the lens

The time delay between exposure to electromagnetic radiation and the response in the lens provides information on the biological consequence of the absorption of electromagnetic energy (Figure 3).

An immediate onset of cataract after the exposure, occurs if the molecular absorption event has a vast impact on the lens. If there is a short delay onset of cataract, usually in the interval (days; $<1$ week) a biological expression of the primary molecular absorption event is

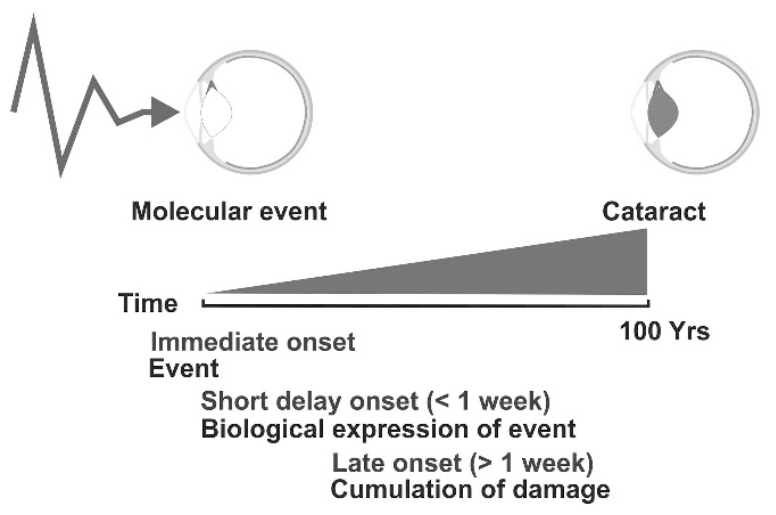

Figure 3 Model for time delay between exposure to electromagnetic radiation and response in the lens. Typically, damage induced by overall heat increase is expressed immediately after the exposure, whereas local heating in the micrometer range and photochemical damage is expressed with a delayed onset depending on the biological response. Photochemical damage may cumulate to late onset damage.

required for cataract to develop. If there is a late onset of cataract, > week, the damage is only expressed when sufficient molecular absorption events are accumulated in relation to biological repair. Typically, experimental data on a potential hazard of UVR or near IRR in the lens are derived from observation of immediate and short delay onset damage. Late onset experimental data are scarce. Epidemiological strategy focuses on associating potential risk factors with late onset cataract.

\section{Damage mechanism}

The lens like any matter has the capacity to store incident photon energy by resonance absorption. If the photon energy corresponds to a specific absorption band in a molecule, absorption occurs as a binary event with a probability defined by the conformity between the incident photon energy and the energy gap available for the molecule to resonate. UVR and short wavelength VIR photon energy corresponds to electron configurations in matter with narrow absorption band. IRR photon energy corresponds to vibration of molecules in matter with broad non-specific absorption bands. Absorption of UVR or short wavelength VIR photons therefore typically alters specific chemical reactivity, photochemical damage, whereas absorption of IRR photons increases vibration that is observed as increased temperature. Large important biomolecules such as protein tend to lose their space structure when vibrating, denaturation. The rate of protein denaturation is determined by a rate constant that is temperature dependent as described by the Arrhenius equation. Damage to biological tissue owing to the high rate of vibration damage is called thermal damage. 


\section{Evidence for UVR damage to the lens}

\section{Epidemiology}

Ever since the 19th century there has been reports on the possibility that long-term exposure to UVR from the sun causes cataract. ${ }^{5}$ Several early epidemiological studies indicated an association between exposure to UVR from the sun and cataract. However, all these studies suffered from incomplete characterization of the ocular exposure. In 1988, Taylor et al ${ }^{6}$ published individual dose estimates by combining meteorological data with interviews of individual sun exposure and found a dose-response relationship between prevalence for cortical cataract and relative individual dose of UVR-B. A careful review of studies on UVR-induced cataract concluded that there was substantial evidence for an association between UVRB and cortical cataract. ${ }^{7}$ In year 2000, an epidemiological study based on personal UVR-dose estimates found that UVR-B was the most important attributable risk factor for cortical cataract possible to prevent. ${ }^{8}$ In 2003, the Reykavik Eye study showed that the ratio for prevalence of cortical cataract in the lower nasal quadrant in relation to the upper temporal was associated with UVR dose (Figure 4). ${ }^{9}$

\section{Experimental evidence}

Experimental in vivo exposure of rat lenses to just above the threshold dose UVR in the 300-nm wavelength range (UVR-300 nm) induces short delay onset cataract with asymptotically increasing forward light scattering up to a week after the exposure. ${ }^{10,11}$ Using observations of induced light scattering after in vivo exposure to

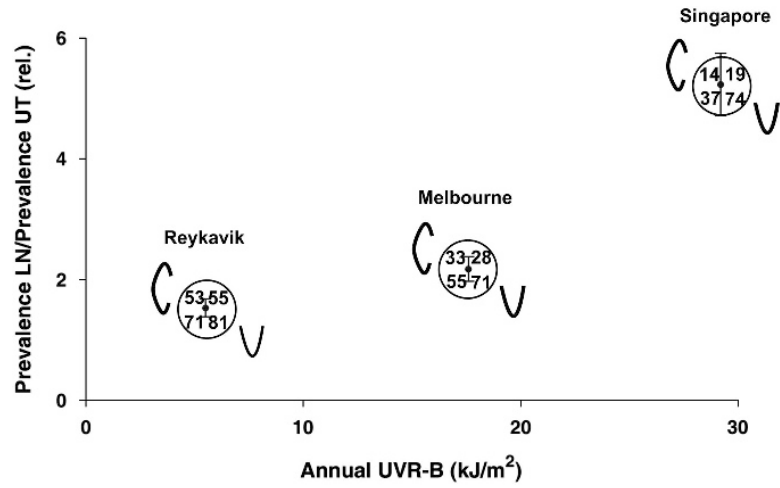

Figure 4 Ratio of prevalence for cortical cataract in the lower nasal quadrant in relation to the upper temporal quadrant (Prev. LN/Prev. UT) as a function of UVR dose. The abscissa shows the estimated annual UVR-B dose in Reykavik, Island (latitude: $64^{\circ} \mathrm{N}$ ), Melbourne, Australia (latitude: $38^{\circ} \mathrm{S}$ ), Singapore, Malaysia (latitude: $1^{\circ} \mathrm{N}$ ). Numbers on plotted coordinate are average prevalences for cortical cataract in upper temporal (upper left), upper nasal (upper right), lower temporal (lower left), and lower nasal (lower right) portion of the lens as estimated by retro-illumination imaging. ${ }^{9}$
UVR-300 nm, it was shown that UVR-induced cataract has a continuous dose-response function (Figure 5). ${ }^{12}$

In order to estimate threshold dose despite the fact that there is no absolute threshold for in vivo UVR-induced cataract, it was suggested to use the maximum tolerable dose, $\left(\mathrm{MTD}_{2.3: 16}\right)$, as a meaningful estimate of toxic dose. ${ }^{13}$

It was demonstrated that reciprocity largely holds for in vivo UVR-300 $\mathrm{nm}$ exposures in the exposure time interval 7.5-120 $\mathrm{min}$, but there is a slightly higher sensitivity with exposure times of around $15 \mathrm{~min}$ (Figure 6). ${ }^{14}$ The slightly higher sensitivity for exposures around $15 \mathrm{~min}$ was attributed to the depletion of preexisting anti-oxidation defense.

It was shown experimentally that in vivo UVR exposure has a characteristic action spectrum typical for photochemical damage, both with qualitative- 15,16 and with quantitative-estimation ${ }^{17}$ of cataract (Figure 7).

Recent in vivo UVR-300 nm experimental daily exposures cumulated for incrementing number of days demonstrated that the threshold dose increases slightly with the length of the number of days during which the dose was cumulated (Figure 8). ${ }^{18}$ These are the first data that demonstrate that cumulated in vivo exposures to a spectrally well-defined source of UVR-300 nm at calibrated irradiance, are additive with a slight impact of

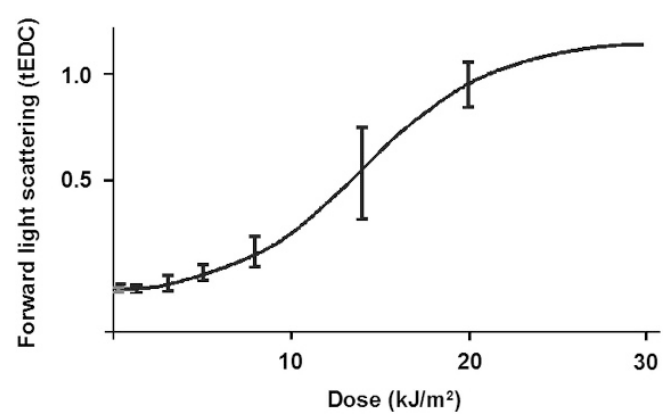

Figure 5 Dose-response function for in vivo UVR-300 nminduced cataract. Intervals are $95 \%$ confidence intervals for the mean $(n=20) .^{12}$

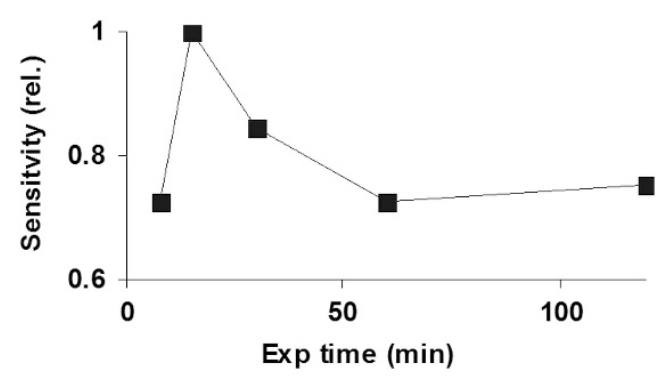

Figure 6 Sensitivity as a function of exposure time at constant radiant exposure dose $\left(\sim 2 \times \mathrm{MTD}_{2.3: 16}\right){ }^{14}$ Square is mean of 20 animals. 


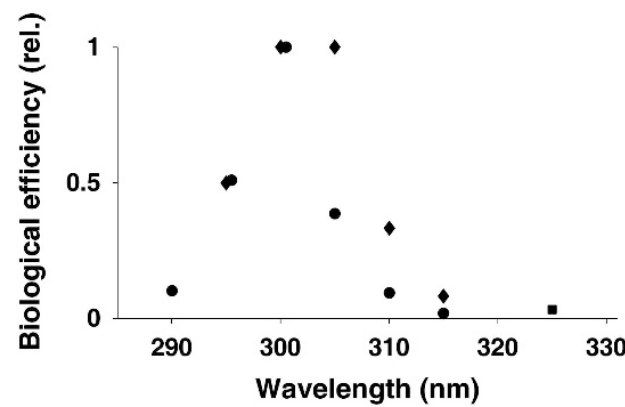

Figure 7 Action spectrum for in vivo UVR-induced cataract. Diamonds are data for individual pigmented rabbits. ${ }^{15}$ Square is data for one monkey. ${ }^{16}$ Circle is mean of 20 albino rats. ${ }^{17}$

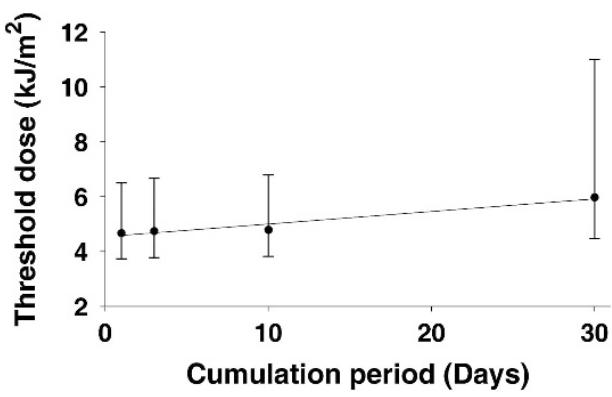

Figure 8 Threshold dose as a function of the period of cumulation of daily in vivo exposures to UVR-300 nm while varying irradiance for different cumulation periods. Threshold dose is estimated as maximum tolerable dose $\left(\mathrm{MTD}_{2.3: 16}\right){ }^{13}$ Bars are $95 \%$ confidence interval for $\mathrm{MTD}_{2.3: 16}$ $(n=20), \mathrm{CI}_{\mathrm{k}}(0.95)=4.5 \pm 3 \mathrm{~kJ} / \mathrm{m}^{-2}(\mathrm{~d} . \mathrm{f}=2){ }^{18}$

biological repair, strongly indicating a photochemical damage in daily exposures.

\section{IRR cataract, photochemical or thermal?}

Several investigations at the end of the 19th century and beginning of the 20th century demonstrated that if IRR is incident on the eye at high irradiance, damage will occur immediately or possibly with short delay onset. ${ }^{19}$ Vogt proposed that cataract after IRR exposure is owing to direct absorption in the lens ${ }^{20}$ but Goldman ${ }^{21}$ was of the opinion that cataract developed owing to heat increase secondary to IRR absorption in the iris.

Near IRR is absorbed in the lens (Figure 2) and thermal damage in the lens after high irradiance IRR exposure is carefully considered in the current safety guidelines. ${ }^{22}$ However, in 1977, Wolbarsht et al ${ }^{23}$ argued that a photochemical effect of near IRR below threshold for thermal damage could not be excluded based on current knowledge and investigated exposures with a CW $1064 \mathrm{~nm} \mathrm{Nd}$ :Yag laser on rabbits (Figure 9). ${ }^{24}$ At the same time, Pitts and Cullen ${ }^{25}$ exposed rabbit eyes using a filtered broad band source. Both Wolbarsht ${ }^{24}$ and Pitts and

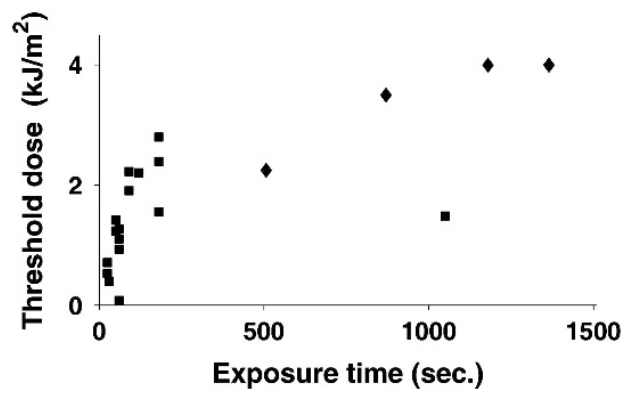

Figure 9 Threshold dose as a function of exposure time for near IRR. Squares are NdYag $1064 \mathrm{~nm}$ exposures. ${ }^{26}$ Diamonds are broadband exposures filtered to $\sim 715-1400 \mathrm{~nm} \cdot{ }^{27}$ All data points are individual animals.

Cullen ${ }^{25}$ claimed to have shown a possible irradianceexposure time reciprocity for threshold dose for near IRR cataract indicating a photochemical effect. However, in both investigations a tendency for reciprocity was only seen in a few data points from single animals and the data could also be interpreted as support for thermal damage.

\section{Epidemiology and IRR cataract}

The observations of Wolbarsht ${ }^{24}$ and Pitts and Cullen ${ }^{25}$ triggered Eva Lydahl ${ }^{26}$ to investigate a possible association between cataract and exposure to IRR in glassand steel works in two case control studies with over 200 cases and controls, respectively, in each study. On the basis of irradiance measurements and patient history of exposure, personal doses were estimated. No dose-effect correlation was found but the exposure to IRR in the cases were reported to facilitate development of age-related cataract.

In the 1980s, there were very few sources present in near IRR and guidelines typically concluded that bulk heat exposure of the human body in some extreme industrial applications that radiate near IRR would exclude toxic exposure. In addition, there is a possibility that a slight temperature increase owing to near IRR absorption thermally increases the rate of denaturation, thus facilitating development of late onset age-related cataract, but this is then a thermal effect.

The current frequent use of near IRR for remote control and sensing demands verification that near IRR does not cause cataract photochemically. ${ }^{27}$ If IRR causes damage photochemically, repeated below threshold exposures could accumulate over time to cause cataract.

\section{Recent experimental investigation of near IRR cataract}

Recent experimental in vivo exposures at $1090 \mathrm{~nm}$ with a CW glass fiber laser where the beam was projected in a $2 \mathrm{~mm}$ spot within the dilated pupil defined the minimum 


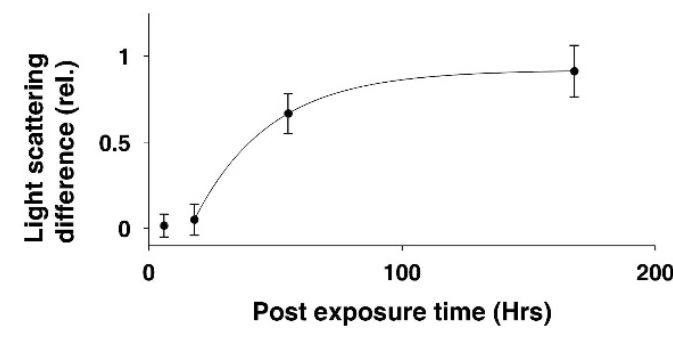

Figure 10 Time evolution of light scattering after in vivo exposure to $200 \mathrm{~W} / \mathrm{cm}^{2} 1090 \mathrm{~nm}$ for $8 \mathrm{~s}$ in a $2 \mathrm{~mm}$ spot within the pupil $\left(1.6 \mathrm{~kJ} / \mathrm{cm}^{2}\right){ }^{29}$ Bars are $95 \%$ confidence intervals (d.f $=19)$ for the mean.

exposure time, at a high irradiance, required to thermally induce cataract and demonstrated a short delay onset cataract (Figure 10). ${ }^{28}$

In a follow-up experiment with the same exposure conditions, temperature measurements at the limbus and close to the optic nerve outside the sclera during the exposure demonstrated that the temperature increase at the limbus was around $10{ }^{\circ} \mathrm{C}$, supporting a thermally induced short delay onset damage. ${ }^{29}$

In a subsequent experiment, exposures with the $1090 \mathrm{~nm}$ beam at $96 \mathrm{~W} / \mathrm{cm}^{2}$ in a $2 \mathrm{~mm}$ spot inside the dilated pupil of a living rat eye was delivered to different groups of animals with incrementing exposure time in the interval 10-60 $\mathrm{min}$, the maximum radiant exposure corresponding to a radiant exposure dose of $340 \mathrm{~kJ} / \mathrm{cm}^{2}$. One eye was exposed and the contralateral eye was kept not exposed as a control. ${ }^{30}$ In all these exposures, the temperature at the limbus increased exponentially within a fraction of a minute to an asymptote below $8^{\circ} \mathrm{C}$ on the exposed side whereas there was no temperature increase on the contralateral side. Light-scattering measurements at 1 week after the exposure did not reveal any significant increase of forward light scattering in the exposed lens or any difference in forward light scattering between the lens from the exposed and the contralateral not exposed lens as measured quantitatively. Thus despite a radiant exposure dose of more than two orders of magnitude higher than that claimed to be the threshold dose for photochemical damage by Wolbarsht ${ }^{24}$ and Pitts and Cullen ${ }^{25}$ there was no sign of cataract. It was concluded that there is no experimental evidence for a photochemical effect at $1090 \mathrm{~nm}$ and that the cataract observed by Wolbarsht ${ }^{24}$ and Pitts and Cullen ${ }^{25}$ was probably because of heating of the iris. However, before a photochemical effect can be safely ignored, other wavelengths should be investigated.

\section{Conflict of interest}

The authors declare no conflict of interest.

\section{Acknowledgements}

We thank Enping Chen, Wen Qian, Stefan Löfgren, Ralph Michael, John Merriam, Linda Meyer, Marcelo Ayala, Xiuquin Dong, Jing Wang, Martin Kronschläger, and Karl Schulmeister who all contributed to several of the investigations cited. This review was made possible by grants from Carmen och Bertil Regnérs fond för forskning, Föreningen Synskadades Vänner i Uppsala Län, Gun och Bertil Stohnes Stiftelse, Konung Gustav V:s och Drottning Victorias Frimurarstiftelse, Kronprincessan Margaretas Arbetsnämnd för synskadade, Ögonfonden, The Uppsala university/Uppsala Läns Landsting's ALF Research grants and Erik Funks Minnesfond.

\section{References}

1 Sliney DH. Physical factors in cataractogenesis: ambient ultraviolet radiation and temperature. Invest Ophthalmol Vis Sci 1986; 27: 781-790.

2 Sliney D. Exposure geometry and spectral environment determine photobiological effects on the human eye. Photochem Photobiol 2005; 81: 483-489.

3 Boettner EA, Wolter JR. Transmission of the ocular media. Invest Ophthalmol 1962; 1: 776-783.

4 Löfgren S, Söderberg PG. Lens lactate dehydrogenase inactivation after UV-B irradiation: an in vivo measure of UVR-B penetration. Invest Ophthalmol Vis Sci 2001; 42(8): 1833-1836.

5 Hirschberg J. Ueber den Star der Glasbläser. Zentralbl F Prakt Augenheilk 1898; 22: 113-117.

6 Taylor HR, West SK, Rosenthal FS, Muñoz B, Newland HS, Abbey $\mathrm{H}$ et al. Effect of ultraviolet radiation on cataract formation. N Engl J Med 1988; 319: 1429-1433.

7 West S. Ocular ultraviolet B exposure and lens opacities: a review. J Epidemiol 1999; 9(6 Suppl): S97-S101.

8 McCarty CA, Nanjan MB, Taylor HR. Attributable risk estimates for cataract to prioritize medical and public health action. Invest Ophthalmol Vis Sci 2000; 41: 3720-3725.

9 Sasaki H, Kawakami Y, Ono M, Jonasson F, Shui YB, Cheng HM et al. Localization of cortical cataract in subjects of diverse races and latitude. Invest Ophthalmol Vis Sci 2003; 44(10): 4210-4214.

10 Michael R, Söderberg PG, Chen E. Long-term development of lens opacities after exposure to ultraviolet radiation at 300 nm. Ophthalmic Res 1996; 28: 209-218.

11 Galichanin K, Löfgren S, Bergmanson J, Söderberg PG. Evolution of damage in the lens after in vivo close to threshold exposure to UV-B radiation: cytomorphological study of apoptosis. Exp Eye Res 2010; 91: 369-377.

12 Söderberg PG, Michael R, Merriam JC. Maximum acceptable dose of ultraviolet radiation: a safety limit for cataract. Acta Ophthalmol Scand 2003; 81(2): 165-169.

13 Söderberg PG, Löfgren S, Ayala M, Dong X, Kakar M, Mody V. Toxicity of ultraviolet radiation exposure to the lens expressed by maximum tolerable dose (MTD). Dev Ophthalmol 2002; 35: 70-75. 
14 Ayala MN, Michael R, Söderberg PG. Influence of exposure time for UV radiation-induced cataract. Invest Ophthalmol Vis Sci 2000; 41(11): 3539-3543.

15 Pitts DG, Cullen AP, Hacker PD. Ocular effects of ultraviolet radiation from 295 to $365 \mathrm{~nm}$. Invest Ophthalmol Vis Sci 1977; 16: 932-939.

16 Ebbers RW, Sears D. Ocular effects of a $325 \mathrm{NM}$ ultraviolet laser. Am J Optom Physiol Opt 1975; 52: 216-223.

17 Merriam JC, Löfgren S, Michael R, Söderberg P, Dillon J, Zheng $\mathrm{L}$ et al. An action spectrum for UV-B radiation in the rat lens. Invest Ophthalmol Vis Sci 2000; 41: 2642-2647.

18 Galichanin K, Löfgren S, Söderberg P. Cataract after repeated daily in vivo exposure to ultraviolet radiation. Health Phys 2014; 107(6): 523-529.

19 Verhoeff FH, Bell L, Walker CB. The pathological effects of radiant energy upon the eye. Proc Am Acad Art Sci 1915; 51: 629-818.

20 Vogt A. Fundamental investigations of the biology of infrared. Klin Monatsbl Augenheilkd 1932; 89: 256-258.

21 Goldmann H. Genesis of heat cataract. Arch Ophthalmol 1933; 9: 314.

22 Stuck B, Schulmeister K, Sliney DH, Lund B, Thomas R, Söderberg PG et al. ICNIRP Guidelines on limits of exposure to incoherent visible and infrared radiation. Health Phys 2013; 105: 74-91.

23 Wolbarsht ML, Orr MA, Yamanashi BS, Zigler JS, Matheson IBC. The orgin of cataracts in the lens from infrared laser radiation. In: Ann Report Contract DAMD 17-74-C-4133, US Army Research and Development Command. Washington, DC, Vol 1977.

24 Wolbarsht ML. Ocular effects of non-ionizing radiation. SPIE Proc 1980; 229: 121-142.

25 Pitts DG, Cullen AP. Determination of Ocular Threshold Levels for Infrared Radiation Cataractogenesis. NIOSH: Cincinnati, OH, USA 1980.

26 Lydahl E. Infrared radiation and cataract. Acta Ophthalmol Suppl 1984; 166: 1-63.

27 Sliney DH. Need for experimental research study of infrared cataract. In: CIE Division 6: Photobiology and Photochemistry Report, Vol. CIE: Geneva, 2006.

$28 \mathrm{Yu}$ Z, Schulmeister K, Talebizadeh N, Kronschläger M, Söderberg PG. $1090 \mathrm{~nm}$ infrared radiation at close to threshold dose induces cataract with a time delay. Acta Ophthalmol 2015; 93(2): e118-e122.

29 Yu Z, Schulmeister K, Talebizadeh N, Kronschläger M, Söderberg PG. Ocular temperature elevation induced by threshold in vivo exposure to $1090-\mathrm{nm}$ infrared radiation and associated heat diffusion. J Biomed Opt 2014; 19(10): 105008-105008.

30 Yu Z, Schulmeister K, Talebizadeh N, Kronschläger M, Söderberg P. Temperature-controlled in vivo ocular exposure to 1090-nm radiation suggests that near-infrared radiation cataract is thermally induced. J Biomed Opt 2015; 20(1): 015003. 